American Journal of Agricultural and Biological Sciences 4 (4): 332-337, 2009

ISSN 1557-4989

(C) 2009 Science Publications

\title{
Farmers' Perception about the Extension Services and Extension Workers: The Case of Organic Agriculture Extension Program by PROSHIKA
}

\author{
${ }^{1} \mathrm{Md}$. Asaduzzaman Sarker and ${ }^{2}$ Yoshihito Itohara \\ ${ }^{1}$ Managerial Economics Division, The United Graduate School of Agricultural Sciences, \\ Tottori University, Japan \\ ${ }^{2}$ Department of Managerial Economics, Faculty of Agriculture, \\ Yamaguchi University, Yamaguchi
}

\begin{abstract}
Problem statement: Need of agricultural information is the basic necessity for the farmers as it plays a pivotal role in enlightening them, raising their level of knowledge and eventually help in their decision making process regarding farming activities. Extension workers with their extension services are doing this noble work. PROSHIKA a renowned NGO in Bangladesh is promoting organic agriculture among the smallholders since 1978. However, its expansion in Bangladesh has remained far behind the expected level that raised the issue about the effectiveness of the organic agriculture extension (from hereafter, OAE) program of PROSHIKA. Thus, the study was undertaken to identify the determinants influencing the effectiveness of PROSHIKA's OAE program in improving the livelihood of the smallholder organic farmers in Bangladesh. Additionally the study was attempted to learn the farmers' perception about this OAE program as well as the Extension Workers (EW). Approach: Data for the analysis were sourced from 90 small holder organic farmers of Madhupur subdistrict those are group members of PROSHIKA. Results: The results of the study showed that the majority (62\%) of the respondent farmers had a good perception about the effectiveness of PROSHIKA's OAE services in their livelihood improvement. While, 50\% of respondent farmers felt that the extension workers of PROSHIKA are credible and about $52 \%$ of the respondent farmers had a better perception about the quality of the extension workers. The result of the logit regression identified that credibility of the extension workers, frequency of contact with extension workers, varieties of extension services received by the farmers and farmers' education had significant relationship with effectiveness of the extension services. Conclusion/Recommendations: Thus it can be concluded that if PROSHIKA give emphasis on credibility improvement of their extension workers and ensure more frequent visits of the extension workers with farmers then the effectiveness of their extension services will be improved and eventually help in rapid expansion of organic farming in Bangladesh.
\end{abstract}

Key words: Perception, extension services, extension workers, organic agriculture and PROSHIKA

\section{INTRODUCTION}

Bangladesh is one of the poorest countries of the world and it has a population of 156 million making it one of the most densely populated countries ${ }^{[1]}$. Most people in Bangladesh make their livings from the land, either as smallholders with an average farm size of 0.76 $\mathrm{ha}^{[2]}$ or as landless agricultural laborers. According to the survey report of Household Income Expenditure Survey of Bangladesh Bureau of Statistics, more than half of its population (56 million people) lives below the poverty line and due to unequal distribution of assets rich people are becoming more rich and poor people getting marginalized ${ }^{[3]}$. According to many scientists like De Jainvry et al..$^{[4]}$ and Hoddinot et al. ${ }^{[5]}$ the poor access to capital assets is perceived as both a symptom and cause of poverty in the developing countries. To create access for the poor farmers to different capital assets, agriculture extension is playing the pivotal role in most developing countries. Department of Agricultural Extension (DAE) as the largest extension organization in Bangladesh is responsible for promoting the latest agricultural technologies among the people of the farming

Corresponding Author: Md. Asaduzzaman Sarker, Managerial Economics Division,

The United Graduate School of Agricultural Sciences, Tottori University, Japan 
community in order to ensure sustainable agricultural growt $^{[6]}$. To fulfill this goal DAE adopted the New Agricultural Extension Policy (NAEP) in 1999. NAEP targeted 11 key components among which "Integrated Environmental Support" was one of the major components. This initiative was taken by DAE due to the accountability of the Government of Bangladesh to protect environmental degradation caused by agrochemicals used in the field of agriculture. However, this initiative of DAE was found as ineffective after a decade as the use of chemical fertilizer and pesticides has increased continuously. A report of the Ministry of Agriculture showed that the consumption of chemical fertilizers has increased around 30\% from 1998-2007 ${ }^{[7]}$ and the total consumption of pesticides has doubled from $1980-2000^{[6]}$. Side by side, the NGO community in Bangladesh is also thriving and playing a key role in the development process, the challenges of poverty reduction and meeting the basic needs of the deprived population. They have also their own agricultural extension services with the purpose of poverty reduction through introduction of high value crops. A few of these NGOs are also promoting eco-friendly agricultural practices among the farming community by different names like ecological agriculture, organic agriculture and permaculture. PROSHIKA a renowned NGO in Bangladesh has been promoting non-certified organic agriculture with the view of livelihood improvement of the smallholders as well as ecological conservation since early 1980s and this organization is the pioneer of introducing organic agriculture in Bangladesh ${ }^{[8]}$. However, in the last 2 decades its expansion remained far behind the expected levels that raised a question to the researchers whether PROSHIKA's extension services are either effective to improve livelihood of the smallholders in Bangladesh. Thus, the researchers take an attempt to learn the farmers' perception about effectiveness of the organic agriculture extension services provided by PROSHIKA as well as their attitude towards the extension workers of PROSHIKA.

Objectives of the study: The specific objectives of the study were:

- To assess organic farmers' access to various extension services provided by PROSHIKA

- To assess the effectiveness of PROSHIKA's OAE program in improving the livelihood of the farmers and explore the associated factors and

- To learn the farmers' perception about the Extension Workers (EWs) of PROSHIKA
PROSHIKA's OAE program: PROSHIKA a renowned NGO in Bangladesh is promoting organic agriculture as a part of its mission to develop a sustainable alternative agro-system and popularize organic agricultural practices. PROSHIKA commenced an action research in 1978. The objective was to produce safe and poison-free food and encourage its group members and other interested people to adopt organic agricultural practices. The organic farms operated by PROSHIKA's group farmers serve two purposes. First of all, the group members and other interested individuals receive hands-on training in organic farming. Secondly, since the vegetables and crops grown in the farm are marketed commercially, it contributes to the development of people's awareness of organic food.

\section{MATERIALS AND METHODS}

Study area: Madhupur sub-district under Tangail district of Bangladesh was deliberately selected for this study. The study area was selected according to research objectives and research works related to the issues. Three villages (Pirojepur, Kuragasa and Lokdeo) of Madhupur sub-district were selected as the study villages. The majority of the people in these villages are farmers and they grow a variety of vegetables and rice by following both conventional and organic methods. However, a significant portion of the smallholder farmers of these villages are growing organic vegetables according to guidelines of Proshika.

Population and sample: The population of the study consisted of all smallholders (landholdings <1 ha) organic farmers (those are involved with PROSHIKA's OAE program) of the three selected villages. Lists of the PROSHIKA farmers was collected from PROSHIKA's Madhupur Area Development Centre (ADC) and from this list a total of 90 farmers were selected (30 farmers from each village) on a random basis.

Data collection: A survey questionnaire was developed matching with the research objectives and used for data collection. The survey was conducted between 10 December 2007 and 10 January 2008. Data was collected from the targeted organic farmers by means of personal interviews. The researchers and three trained assistants were involved in interviewing the respondent farmers. An appointment was made with the respondent farmers via technical worker of PROSHIKA prior to data collection. The raw data from the survey was 
coded and inserted in to computer data base and finally data analyzed with SPSS v 17 software.

Measurement of the dependent variable: Effectiveness of the PROSHIKA's OAE program was the dependent variable of the study and was measured based on the respondent farmers' perception about the performance of the program in improving the issues like knowledge and skill, crop production, income, confidence, well-being, environmental awareness, health awareness, knowledge on balance use of natural resources. A respondent farmer was intended to choose either yes or no for each issues and the score was assigned 1 for yes and 0 for no. Finally, the summation of all ten selected issues for a respondent farmer was completed and it indicated his perception score regarding the effectiveness of PROSHIKA's OAE program. For regression analysis this score of a farmer was converted in to dummy variable (perception score up to $5=0$; perception score $>5=1$ ).

\section{RESULTS}

Services received by the farmers from PROSHIKA's OAE program: As the study was aimed to learn the farmers' perception about the effectiveness of PROSHIKA's organic agriculture extension program in improving the livelihood of the small holders in Bangladesh, thus an attempt was taken to learn about the available extension services provided by PROSHIKA's organic agriculture extension program as well as farmers' access to those services. To fulfill this purpose prior to survey work a Focus Group Discussion (FGD) was conducted with the participation PROSHIKA's extension workers as well as the organic framers of the study villages. The results of the FGD explored that PROSHIKA's OAE program is providing 8 types of services to their group farmers for producing organic vegetables and crops. Later, these 8 services were incorporated on the questionnaire to learn whether a respondent farmer is receiving all these services and the summary of the findings are shown in Table 1.

The results of the study showed that the majority of the farmers had access to organic product marketing time to time monitoring of the organic farms by the extension workers, supply of technical information and credit. On the other hand, the majority of the farmers had limited access to organic inputs, training on organic farming and lessons about balance use of natural resources.

Farmers' perception about PROSHIKA's OAE program: The main objective of the study was to assess the effectiveness of the PROSHIKA's organic agriculture extension program in improving the livelihood of the smallholders. To fulfill this objective, the farmers' perception was learned and the summary of this analysis are presented in Table 2 .

Table 1: Farmers' access to different services provided by PROSHIKA's OAE program

\begin{tabular}{|c|c|c|c|c|}
\hline \multirow[b]{2}{*}{ Extension services } & \multicolumn{2}{|c|}{ Have access } & \multicolumn{2}{|c|}{ Have no access } \\
\hline & Number & Percent & Number & Percent \\
\hline Training on organic agriculture & 48 & 53.3 & 42 & 46.7 \\
\hline Credit for doing organic agriculture & 60 & 66.7 & 30 & 33.3 \\
\hline Organic inputs (seeds, manure, herbal or bio-pesticides) & 32 & 35.6 & 58 & 64.4 \\
\hline Technical information & 69 & 76.7 & 21 & 23.3 \\
\hline Method demonstration (compost and herbal pesticide preparation) & 58 & 64.4 & 32 & 35.6 \\
\hline Lessons about balance use of natural resources & 49 & 54.4 & 41 & 45.6 \\
\hline Time to time monitoring of the organic farm & 70 & 77.8 & 20 & 22.2 \\
\hline Assistance in organic product marketing & 72 & 80.0 & 18 & 20.0 \\
\hline
\end{tabular}

Source: Authors' survey, 2008

Table 2: Farmers' perception about the effectiveness of PROSHIKA's OAE program in improving the selected issues $(\mathrm{N}=90)$

\begin{tabular}{|c|c|c|c|c|}
\hline \multirow[b]{2}{*}{ Issues } & \multicolumn{2}{|l|}{ Effective } & \multicolumn{2}{|c|}{ Not effective } \\
\hline & Number & Percent & Number & Percent \\
\hline Knowledge and skill development & 86 & 95.60 & 4 & 4.40 \\
\hline Increase crop production & 54 & 60.00 & 36 & 40.00 \\
\hline Income improvement & 75 & 83.33 & 15 & 16.66 \\
\hline Confidence development & 68 & 75.55 & 22 & 24.44 \\
\hline Improve well-being & 55 & 61.11 & 35 & 38.89 \\
\hline Improve capacity to face adverse situation & 16 & 17.78 & 74 & 82.22 \\
\hline Environmental awareness generation & 51 & 56.67 & 39 & 43.33 \\
\hline Development of health awareness & 46 & 51.11 & 44 & 48.89 \\
\hline Improve knowledge on balanced use of natural resources & 42 & 46.67 & 48 & 53.33 \\
\hline Overall livelihood improvement & 61 & 67.78 & 29 & 32.22 \\
\hline
\end{tabular}

Source: Authors' survey 2008 
Am. J. Agri. \& Biol. Sci., 4 (4): 332-337, 2009

Table 3: Farmers' perception about the effectiveness of PROSHIKA's OAE program in three study villages $(\mathrm{N}=90)$

\begin{tabular}{|c|c|c|c|c|c|c|c|c|}
\hline \multirow[b]{2}{*}{ Categories } & \multicolumn{2}{|c|}{ Pirojepur $(\mathrm{n}=30)$} & \multicolumn{2}{|c|}{ Kuragasa $(\mathrm{n}=30)$} & \multicolumn{2}{|c|}{ Lokdeo $(\mathrm{n}=30)$} & \multicolumn{2}{|c|}{ Total $(\mathrm{N}=90)$} \\
\hline & Number & Percent & Number & Percentage & Number & Percentage & Number & Percentage \\
\hline Not effective (up to 5) & 17 & 56.67 & 5 & 16.67 & 12 & 40.0 & 34 & 37.78 \\
\hline Effective (more than 5) & 13 & 43.33 & 25 & 83.33 & 18 & 60.0 & 56 & 62.22 \\
\hline
\end{tabular}

Source: Authors' analysis

Table 4: Organic framers' perception about the extension workers of PROSHIKA

\begin{tabular}{|c|c|c|c|c|}
\hline \multirow[b]{2}{*}{ Issues } & \multicolumn{2}{|l|}{ Agreed } & \multicolumn{2}{|c|}{ Not agreed } \\
\hline & Number & Percentage & Number & Percentage \\
\hline Extension workers have sufficient quality & 47 & 52.0 & 43 & 48.0 \\
\hline Extension workers are credible & 45 & 50.0 & 45 & 50.0 \\
\hline Extension workers communicate frequently & 42 & 46.7 & 48 & 53.3 \\
\hline
\end{tabular}

Source: Authors' survey, 2008

The results of the study as shown in Table 2 indicates that due to organic farming extension program of PROSHIKA $95.6 \%$ of the respondent farmers have gained knowledge and skill development regarding organic cultivation methods and $60 \%$ of them attained increased crop production. The earlier Table 2 also shows that due to PROSHIKA's OAE program absolute majority $(83 \%)$ of the respondent farmers have achieved income improvement. This is due to the reason that previously they used to cultivate only rice but after introduction of PROSHIKA's organic farming program they are cultivating high value crops as well as enjoying the price premium of organic products. Thus, a significant portion of the respondent farmers $(61 \%)$ have gained family well-being as a result of this extension program. On the other hand, around half of the respondent farmers mentioned that due to this extension program they are more aware of health and environmental issues and gained knowledge on balanced use of natural resources. While only a small $(18 \%)$ number farmers have reported that this extension program is effective in raising their capacity to face adverse situation. However, around two-thirds (68\%) of the respondent farmers noticed that PROSHIKA's OAE program is effective in improving their overall livelihood.

Based on the total score of the above mentioned selected issues the perception of a farmer regarding the effectiveness of PROSHIKA's OAE program was calculated and the summary is presented in Table 3.

The results shown in Table 3 shows that among the respondent farmers, a significant portion (62\%) hold a positive perception that PROSHIKA's OAE program is effective in improving their livelihood. The positive perception towards PROSHIKA's OAE program is relatively higher among the farmers of Kuragasa village. The absolute majority (83\%) of the farmers of Kuragasa village hold the perception that PROSHIKA's
OAE program is effective in improving their livelihood. On the contrary, the positive perception towards PROSHIKA's OAE program was lowest $(43 \%)$ in Pirojepur village. This is due to the reason that Pirojepur village is distant from the Madhupur upazila headquarters. Thus, they have relatively less communication with extension workers of Proshika compared to the other two project villages. On the other hand, Kuragasa is itself a growth center in this area, so farmers usually gather here every day and the extension worker of PROSHIKA also uses this opportunity to communicate with the farmers.

Farmers' perception about the extension workers of PROSHIKA: Another important objective of the study was to learn the organic farmers' perception about the extension workers of PROSHIKA. With this regard farmers' opinion was taken about three aspects of an extension worker and these were extension workers' quality, to what extent he/she is credible to the farmers and how frequently he/she has communication with the farmers. Finally, the results of the farmers' perception about the extension workers working with PROSHIKA's OAE program are shown in Table 4.

To learn about the quality of an extension worker, a respondent farmer was asked to give his opinion about the extension workers' educational background, ability to provide updated information, technical knowledge, communication ability and perception about organic farming. If the respondent farmer gives positive response against all issues then it was treated that the farmer has positive perception about the extension worker's quality and was assigned score 1 , otherwise 0 . Similarly, an extension worker's credibility was measured based on the perception of a farmer regarding the issues like to what extent the extension worker is responsible, keep their word when they make an appointment with a farmer and feelings about the organic farmers. 
Am. J. Agri. \& Biol. Sci., 4 (4): 332-337, 2009

Table 5: Determinants of effectiveness of PROSHIKA's OAE program by Logit regression

\begin{tabular}{|c|c|c|c|c|c|}
\hline & \multirow[b]{2}{*}{ Independent variables } & \multicolumn{4}{|c|}{ Parameter estimates } \\
\hline & & $\mathrm{B}$ & Std. error & $\mathrm{Z}$ & Sig. \\
\hline \multicolumn{6}{|c|}{ Dependent variable: Effectiveness of PROSHIKA's OAE program in improving livelihood } \\
\hline \multirow{5}{*}{ Socio-demographic indicators } & Age & 0.727 & 0.545 & 1.334 & 0.182 \\
\hline & Gender & -0.529 & 0.623 & -0.849 & 0.396 \\
\hline & Education & -0.137 & 0.079 & -1.740 & $0.082 * *$ \\
\hline & Farm holdings & -2.901 & 2.886 & -1.005 & 0.315 \\
\hline & Household income & 0.004 & 0.007 & 0.592 & 0.554 \\
\hline \multirow{6}{*}{ Organic agricultural extension related indicators } & Number of services received & 0.505 & 0.189 & 2.675 & $0.007 * * *$ \\
\hline & Frequency of contact & 1.398 & 0.535 & 2.615 & 0.009 *** \\
\hline & Perception about EW's quality & 0.236 & 0.155 & 1.517 & 0.129 \\
\hline & Credibility of the EW & 1.218 & 0.592 & 2.058 & $0.040 * *$ \\
\hline & Barrier in communicating with EW & -0.025 & 0.207 & -0.123 & 0.902 \\
\hline & Intercepts & -3.737 & 1.305 & -2.864 & 0.004 \\
\hline$\chi^{2}$ statistics with $10 \mathrm{df}$ & $48.25(\mathrm{p}<0.000)$ & & & & \\
\hline LR & 41.18 & & & & \\
\hline Pseudo $\mathrm{R}^{2}$ & 0.58 & & & & \\
\hline
\end{tabular}

A respondent farmer was asked whether the extension worker communicated with him sufficiently. The results of the study showed that almost half of the respondent farmers perceived that the extension workers are qualified enough to promote organic agriculture among the farmers as well as they are credible to the farmers. The other half of the farmers had the completely opposite perception. However, more than half $(53 \%)$ of the respondent farmers had stated that the extension workers do not communicate with the farmers frequently enough.

Factors associated with effectiveness of
PROSHIKA's OAE program in livelihood improvement of the smallholders: The main purpose of the study was to explore the important factors that can influence effectiveness of the PROSHIKA's OAE program in improving the livelihood of the small farmers. To fulfill this purpose logistic regression analysis was done and results are shown in Table 5. The results of the study showed that log likelihood ratio of the study is 41.18 and chi-square statistics for goodness of fit of the model is 48.25 that are significant at $1 \%$ level of significance. The pseudo $\mathrm{R}^{2}$ value of the model is 0.58. Thus, the overall model is significant and the explanatory variables used in the model collectively can explain the effectiveness of PROSHIKA's organic agriculture extension program.

The results of the logit model identified 4 factors out of 10 as significant for effectiveness of PROSHIKA's OAE program for improving livelihood of the smallholder farmers and these were: farmers' education, number of extension services received by the farmers, frequency of contact of the EW with farmers and credibility of the EWs. Among the abovementioned
4 explanatory variables except farmers' education, all had positive significant relationship with effectiveness of PROSHIKA's OAE program. The reason of negative relationship between farmer's education and effectiveness of PROSHIKA's OAE program in improving the livelihood of the farmers was PROSHIKA's priority to work with the resource poor farmers who are usually less or not educated. However, the aforementioned Table 5 also shows that among the significant variables: The number of extension services received by the farmers and frequency of contact with the EW were significant at $1 \%$ level of significance. On the other hand, farmers' education and credibility of the EW were significant at $5 \%$ level of significance.

\section{DISCUSSION}

As the extension agent is the best source of information and training for farmers' participatory development, thus their credibility is very important for effective extension services. Similarly, the more frequent contact with the extension workers is also important for improving the effectiveness of the extension services. When the farmers have more frequent contact with the EW then they can get more reliable information from them, as well as the EW also become more credible with the farmers through regular reciprocal communication. These hypotheses are sustained by the findings of Oladosu ${ }^{[9]}$.

\section{CONCLUSION}

The results of the study revealed that PROSHIKA's OAE program is providing a variety of services among the small holder organic farmers in 
Bangladesh. The results of the study also showed that PROSHIKA is giving priority to provide only credit, technical information, monitoring the farm and helping the farmers in marketing their organic products. So, it can be concluded that PROSHIKA should be given priority to other important services like training, knowledge on balance use of natural resources and supplying organic inputs as the logit method explored that uses of variety of services has significant influences on increasing effectiveness of their extension program in improving the livelihood of the small holders. The study also confirmed that according to the perception of the majority of farmers PROSHIKA's OAE program is found effective in improving the livelihood of the smallholder farmers. However, they have some complaints about the credibility of the EW as well as the frequency of contact with the EW and these variables are found as significant with effectiveness of the OAE program in the logit regression model. Thus, the concerned extension organization should be taken into account to increase the credibility of their EWs as well as they need to ensure highest frequency of contact with the farmers. The results of the logit model also showed that PROSHIKA's OAE program has basically targeted less educated farmers, so if they include the highly educated farmers in future that might give better success in OAE in Bangladesh. Finally, it can be concluded that considering all these factors PROSHIKA should fine tune their OAE program which will ultimately increase the effectiveness of the program in improving livelihood of the poor farmers as well as contribute in environmental protection in Bangladesh.

\section{REFERENCES}

1. World Factbook, 2009. The online world fact book. Central Intelligence Agency (CIA), United States of America.

https://www.cia.gov/library/publications/theworld-factbook/geos/bg.html

2. Ilangantilekel, S.G., M.S. Kadian1, M. Hossain, A.E. Hossain, U. Jayasinghe and A.A. Mahmood, 2000. Toward alleviating poverty of rural potato farmers by strengthening the potato seed system in Bangladesh: A rapid rural appraisal. CIP Program Report, 1999-2000.

http://www.cipotato.org/potato/tps/docs/32seedBan gldsh.pdf
3. Household Income Expenditure Survey (HIES), 2005. Household Income and Expenditure Survey Report 2005. Bangladesh Bureau of Statistics, Planning Division, Ministry of Planning, Government of the People's Republic of Bangladesh. In Bangladesh Quarterly Economic Update, Asian Development Bank (ADB). http://www.adb.org/Documents/Economic_Update s/BAN/2006/sep-2006.pdf

4. De Janvry, A., E. Sadoulet, P. Solomon and R. Vakis, 2006. Uninsured risk and asset protection: Can conditional cash transfer programmes serve as safety-nets? SP Discussion paper 0604. Social Risk Management SeriesWorld

Bank. http://siteresources.worldbank.org/SOCIAL PROTECTION/Resources/SP-Discussionpapers/Social-Risk-Management-DP/0604.pdf

5. Hoddinott, J., 2006. Shocks and their consequences across and within households in rural Zimbabwe. J. Dev. Stud., 42: 301-321. http://www.aae.wisc.edu/aae732/papers/hoddinott $\% 20 \mathrm{jds} . p d f$

6. National IPM Policy, 2002. National integrated pest management policy, 2002. Ministry of Agriculture, Government of the People's Republic of Bangladesh.

http://www.dae.gov.bd/Pdf\%20forms/Policy/IPM.p df

7. Department of Agricultural Extension (DAE), 1999. Agricultural Extension Manual, Ministry of Agriculture, Government of the People's Republic of Bangladesh.

http://www.dae.gov.bd/Pdf\%20forms/Book/Extens ion_Mannual_Chapt1.pdf

8. PROSHIKA, 2007. Annual report of PROSHIKA, Bangladesh. http://www.proshika.org/ar_2007.pdf

9. Oladosu, I.O., 2006. Implications of farmers' attitude towards extension agents on future extension programme planning in Oyo State of Nigeria. J. Soc. Sci., 12: 115-118. http://www.krepublishers.com/.../JSS-12-2-115118-2006-258-Oladosu-I-O-Text.pdf 